\title{
Genetic transfer from several apomictic tetraploid Paspalum species to an elite group of sexual plants
}

\author{
Patricia E. Novo ${ }^{1,2}$ ｜ Carlos A. Acuña ${ }^{1,2}$ (6) | Mario H. Urbani ${ }^{1,2} \quad$ | Florencia Galdeano ${ }^{1,2}$ | \\ Francisco Espinoza ${ }^{1,2}$ (1) | Camilo L. Quarin ${ }^{1,2}$
}

${ }^{1}$ Universidad Nacional del Nordeste, Facultad de Ciencias Agrarias, Corrientes, Argentina

${ }^{2}$ Instituto de Botánica del Nordeste,

CONICET-UNNE, Corrientes, Argentina

Correspondence

Francisco Espinoza, Universidad Nacional del Nordeste, Facultad de Ciencias Agrarias,

Corrientes, Argentina.

Email: espinoza@agr.unne.edu.ar

\section{Funding information}

Consejo Nacional de Investigaciones Científicas y Técnicas, Grant/Award Number: PIP No. $1220150100105 \mathrm{CO}$; Universidad Nacional del Nordeste, Grant/Award Number: PI 17A012; Fondo para la Investigación Científica y Tecnológica, Grant/Award Number: PICT2015 No. 0158; FCA-PGG Wrightson Seeds cooperation agreement

Assigned to Associate Editor Joseph Robins.

\begin{abstract}
Basic findings from classical genetic studies are available for exploiting apomixis in the breeding of several forage grass genera. Most Paspalum species are multiploid with a sexual diploid cytotype and conspecific apomictic polyploid (mainly tetraploid) cytotypes. Experimental tetraploidized diploids reproduce sexually and, when crossed with natural apomictic tetraploids, yield hybrid populations that segregate for reproductive mode. Genetic studies indicated that apomixis is inherited as a monogenic dominant factor. We recombined 50 selected sexual hybrids obtained from crosses between a tetraploidized sexual genotype of $P$. plicatulum and 9 natural apomictic tetraploid accessions of 6 species of the Plicatula group. A synthetic sexual tetraploid population (SSTP) of 600 individuals from mixed seed of the 50 intercrossed hybrids was space-planted in the field. Based on evaluations of plant vigor, seed set, ergot tolerance, regrowth after flowering, and cold tolerance, 31 plants were selected. Crosses between most selected plants and two testers, which belonged to $P$. guenoarum, were performed, and the generated progeny was planted into the field following a randomized block design with 3 replications. The progeny test was evaluated for seed fertility, biomass yield, and cold tolerance. This procedure allowed selection of 10 elite plants from the SSTP. These plants should contain genes recombined from six apomictic species, without the genetic determinants for apomixis. They may be polycrossed to generate an improved sexual population, or crossed with other apomictic genotypes to obtain improved apomictic hybrids.
\end{abstract}

\section{1 | INTRODUCTION}

The grass genus Paspalum comprises a large number of species, mainly native to the Americas. Most species have a basic chromosome number of $\mathrm{x}=10$; polyploidy is common in the genus. According to their ploidy levels and reproductive

\footnotetext{
Abbreviations: 4PT, sexual induced-tetraploid P. plicatulum; LSD, Fisher's Least Significant Difference; PP, polycross population; SSTP, sexual synthetic tetraploid population.
}

(C) 2020 The Authors. Crop Science () 2020 Crop Science Society of America modes Paspalum species may be classified in at least four main categories: (1) diploids, which reproduce sexually; (2) multiploids, which occurs in many species, usually contain both sexual diploid (2x) and apomictic tetraploid (4x) cytotypes, but also may have $3 x$ and $6 x$, or even other apomictic cytotypes such as $5 \mathrm{x}$ and $7 \mathrm{x}$, in addition to $2 \mathrm{x}$ and $4 \mathrm{x}$. Usually, tetraploid is the most common cytotype in the majority of multiploid Paspalum species (Quarin, 1992). They exhibit a variable degree of multivalent chromosome associations at meiosis, mainly quadrivalents, also trivalents, and exceptionally some higher associations that may vary 
from a pentavalent to an octavalent. In consequence, they have usually been classified as autotetraploids or segmental allotetraploids; (3) apomictic polyploids bearing a single ploidy level (mainly tetraploids), that may exhibit either multivalent chromosome associations or quite irregular chromosome pairing at meiosis; (4) sexual polyploids, mainly tetraploids and hexaploids with regular bivalents chromosome pairing at meiosis, a characteristic feature of allopolyloids of hybrid origin. These constitute the less common category, while multiploidy is the most common one in Paspalum (Acuña et al., 2019; Ortiz et al., 2013; Quarin, 1992). All polyploid cytotypes of multiploid species reproduce by apomixis though some plants may show some potential for sexual reproduction. Completely sexual polyploid plants have never been found in the wild in any apomictic Paspalum species at the same polyploid level (Ortiz et al., 2013).

Apospory, parthenogenesis, and pseudogamy are the usual components of most apomictic Paspalum species. The aposporous unreduced embryo sacs develop from nucellar cells. Facultative apomictic species may have a welldeveloped meiotic embryo sac together with one to several aposporous sacs in some ovules, or sexual and aposporous sacs may occur in different ovules (Ortiz et al., 2013).

Nowadays, a very efficient tool for determining reproductive mode is available using flow-cytometry to assess the deoxyribonucleic acid (DNA) content in mature seeds (Matzk, Meister, \& Schubert, 2000). The method is especially applicable for apomictic Paspalum species because aposporous embryo sacs in this genus have two polar nuclei in the central cell. The unreduced egg cell produces the embryo through parthenogenesis and the endosperm develops from the fusion of the two unreduced polar nuclei and a meiotically reduced sperm nucleus (pseudogamy). Then, the resulting seed of an apomictic individual has an embryo:endosperm DNA content ratio of $2: 5$, while a sexually reproducing individual gives rise to seeds with a ratio of 2:3.

The Plicatula group is a subgeneric taxonomic category of approximately 30 species. The group includes both perennial multiploids and apomictic tetraploids, with some fairly infrequent annual polyploids which reproduce sexually. Most species of Plicatula group are valuable forage grasses, constituents of native grasslands. For this group, only a few apomictic tetraploid species or tetraploid cytotypes of multiploid species have been brought into cultivation for forage in the Americas, and also in Australia and other tropical or subtropical areas of the world: $P$. plicatulum Michx., $P$. guenoarum Arechav., $P$. nicorae Parodi, $P$. atratum Swallen (Evers \& Burson, 2004; Oram, 1990). Because these tetraploids of the Plicatula group reproduce by apomixis, all cultivars come from the direct selection of superior biotypes collected in the wild in South or in Central America. No current forage cultivar has been produced by genetic improvement through artificial hybridization in any species of the Plicatula group (Evers \& Burson, 2004). In order to broaden the genetic basis available to plant breeders, the challenge was to break the genetic combinations anchored in apomictic tetraploids. In fact, these apomictic tetraploids maintain functional reduced pollen formed through meiosis. However, the lack of completely sexual reproducing plants in natural populations of apomictic tetraploid species greatly restricts gene transfer through male gametes. These natural conditions have constrained the breeding of these species due the historical impossibility of making crosses to recombine genes. Opening the possibility of gene recombination through sexual $\times$ apomictic crosses, would open chances to acquire some agronomic superior apomictic genotypes by selecting among the apomictic part of the progeny. These chances would increase by widening the genetic basis of experimentally obtained sexual plants.

Two sexual autotetraploid plants of $P$. plicatulum were previously obtained by colchicine treatment of the conspecific sexual diploid cytotype. The tetraploidized plants reproduce entirely sexually. One is completely self-incompatible (4PT) and the other highly self-incompatible (7PT), and they are mutually cross-compatible (Sartor, Quarin, \& Espinoza, 2009). Aguilera, Galdeano, Quarin, Ortiz, and Espinoza (2015) hybridized the tetraploidized sexual plants of $P$. plicatulum with an apomictic tetraploid plant. Their results suggested a monogenic, dominant control in a frame of polysomic inheritance at the tetraploid level. This suggestion was based on key facts: sexual $\times$ apomictic $F_{1}$ hybrids segregated for reproductive mode; sexual $\mathrm{F}_{1}$ hybrids always produced exclusively sexual progenies under circumstances of selfing, or cross-pollination with other sexual $F_{1}$ genotype, and also backcrosses to the sexual parent; apomictic $\mathrm{F}_{1}$ hybrids backcrossed to female parent or crossed to sexual $\mathrm{F}_{1} \mathrm{~s}$ always segregated for reproductive mode. A number of interspecific hybrids were obtained when sexual tetraploidized plants were pollinated with 16 different accessions involving 9 natural apomictic tetraploid species of the Plicatula group, though with different degrees of crossability (Aguilera, Sartor, Galdeano, Espinoza, \& Quarin, 2011; Novo et al., 2017).

At the present time, the available knowledge about ploidy levels, reproductive mode, crossability, chromosome pairing, and cytogenetic relationships, makes it possible to hypothesize that any genetic factor occurring in apomictic tetraploids of several species of the Plicatula group might be recombined in a synthetic sexual population. Simultaneously, it would be possible to select agronomically superior genotypes, fixed by apomictic reproduction, at any point in a series of cyclic crosses and backcrosses through cross-pollination of synthetic sexual plants with apomicts.

Based on the reproductive mode of the obtained intraand interspecific hybrids the program was divided in two branches: (1) the agronomic evaluation of the apomictic $F_{1}$ 
hybrids, and (2) the recombination of genes among the sexual $\mathrm{F}_{1}$ hybrids for a rapid selection of a group of sexual plants, bearing a wider genetic basis than the two autotetraploidized plant derived from a diploid genotype of $P$. plicatulum. Therefore, more than 90 apomictic hybrids entered in a separate project. This part of the program is underway including selection based on several agronomic characteristics and with the final purpose of registration of some superior apomictic lines for cultivation. Simultaneously with the work with apomictic hybrids, the branch of the program described in this work was initiated. This phase of the program required handling a large number of sexual hybrids during two cycles of crossings: first, a polycross involving vigorous plants from different hybrid families rapidly selected by visual traits and by their capacity to produce seed in cross pollination; second, to select a group of a few sexual hybrids derived from the polycross. Due to its hybrid origin, this elite group is expected to have genes introgressed from apomictic tetraploids. This group should carry a much wider genetic basis than our induced sexual autotetraploid P. plicatulum. These sexual plants will constitute new female parents in future crosses addressed to plant improvement of apomictic tetraploid species of the Plicatula group. The objectives of this research were: (1) to create a polycross population (PP) for recombining selected sexual hybrids previously obtained by crossing one tetraploidized sexual, selfincompatible plant of $P$. plicatulum, named 4PT, with natural apomictic tetraploid genotypes of several species of the Plicatula group, (2) to establish in the field a large sexual synthetic tetraploid population (SSTP) derived from the PP, (3) to select in this SSTP those hybrids superior on general agronomic performance, considering phenotypic and genotypic information. The selected genotypes from SSTP are expected to bear an array of genetic recombinations from 6 apomictic species $(9$ accessions) of the Plicatula group, but without the genetic factor that determines apomictic reproduction.

\section{2 | MATERIALS AND METHODS}

\section{1 | Background of plant material}

Previously, intra- and interspecific hybrids had been produced by cross-pollinating the sexual, self-sterile tetraploidized genotype 4PT of $P$. plicatulum with pollen of 6 natural apomictic tetraploid species of the Plicatula group, including 9 different accessions (Aguilera et al., 2011; Novo, Espinoza, \& Quarin, 2013, 2016, 2017, 2019). We used some sexual $\mathrm{F}_{1}$ hybrids whose apomictic tetraploid male parents were the following species and accessions: Hojs 388 of P. plicatulum; ST13894 of P. chaseanum; GR19, Azulao, Baio, and Q4108 of $P$. guenoarum; V11893 of $P$. lenticulare; PI508821 of $P$. nicorae; and A\&V1332 of P. oteroi. Previous cytological studies of these hybrids and their parents indicated that all natural tetraploid species used as male parents may be classified as autotetraploids or segmental allopolyploids, and all of them share a similar basic genome or they share genomes with some degree of homology with the autotetraploidized plant 4PT of $P$. plicatulum. Though in different degrees, allosyndetic chromosome pairing were observed in all these intra- or interspecific hybrids (Aguilera et al., 2011; Novo et al., 2013, 2016, 2019). These cytogenetic results have indicated that all these hybrids may be classified as polyploid with variable degrees of segmental allotetraplody.

\section{2 | Fertility}

Taking into account that the female parent 4PT is a sexual allogamous plant (self-incompatible, but cross-compatible) and all male parents are apomictic, pseudogamous, and autogamous (self-compatible), the pollinating system of the hybrids was determined. Thus, fertility under self- and openpollination was determined for most of the sexually reproducing hybrids used in this work in order to determine their capacity for naturally intercrossing in the polycross population (PP) in a space-planted stand. Self-pollination was obtained by keeping inflorescences into glassine bags from before anthesis until seed maturity and harvest. Free openpollinated inflorescences were bagged after they completed blooming and harvested at seed maturity. Both self- and open-pollination were conducted either in large stands of pot-grown hybrid plants in a greenhouse or transplanted in the field. The stands contained several plants from different hybrid combinations. Mature inflorescences were threshed by hand. The empty spikelets were separated in a blower from those filled with grain in order to establish the proportion of seed set. Then, the healthy grains were separated from those infected with ergot (Claviceps paspali) under a stereoscopic microscope.

Fertility in controlled crosses between specific pairs of sexual hybrids was assessed. Reciprocal crosses between random pairs of hybrids were conducted to determine how the selected sexual $F_{1}$ hybrids would behave in a PP. The total possibility of reciprocal crosses of $50 \mathrm{~F}_{1}$ hybrids would imply a tremendous task of 2450 different crosses. Thus, we decided to make illustrative reciprocal crosses between randomly chosen pairs of $\mathrm{F}_{1} \mathrm{~s}$ that were members of the same or from different hybrid families just to have an idea that reciprocal crosses will occur in the PP. Reciprocal crosses were executed without previous emasculation of the pollinated plant.

\section{3 | The polycross population}

One intraspecific and eight interspecific families had originally been obtained, comprising 383 hybrids (Novo et al., 
T A B L E 1 Intra- and interspecific sexual $\times$ apomictic crosses involved in the formation of a polycross population (PP) of sexually reproducing hybrids in the Plicatula group of Paspalum: number of hybrids analyzed for reproductive mode; selected sexual hybrids and their fertility (proportion of spikelets that set seed) under different conditions; clonal propagules per hybrid and number of plants established in the field to form the PP

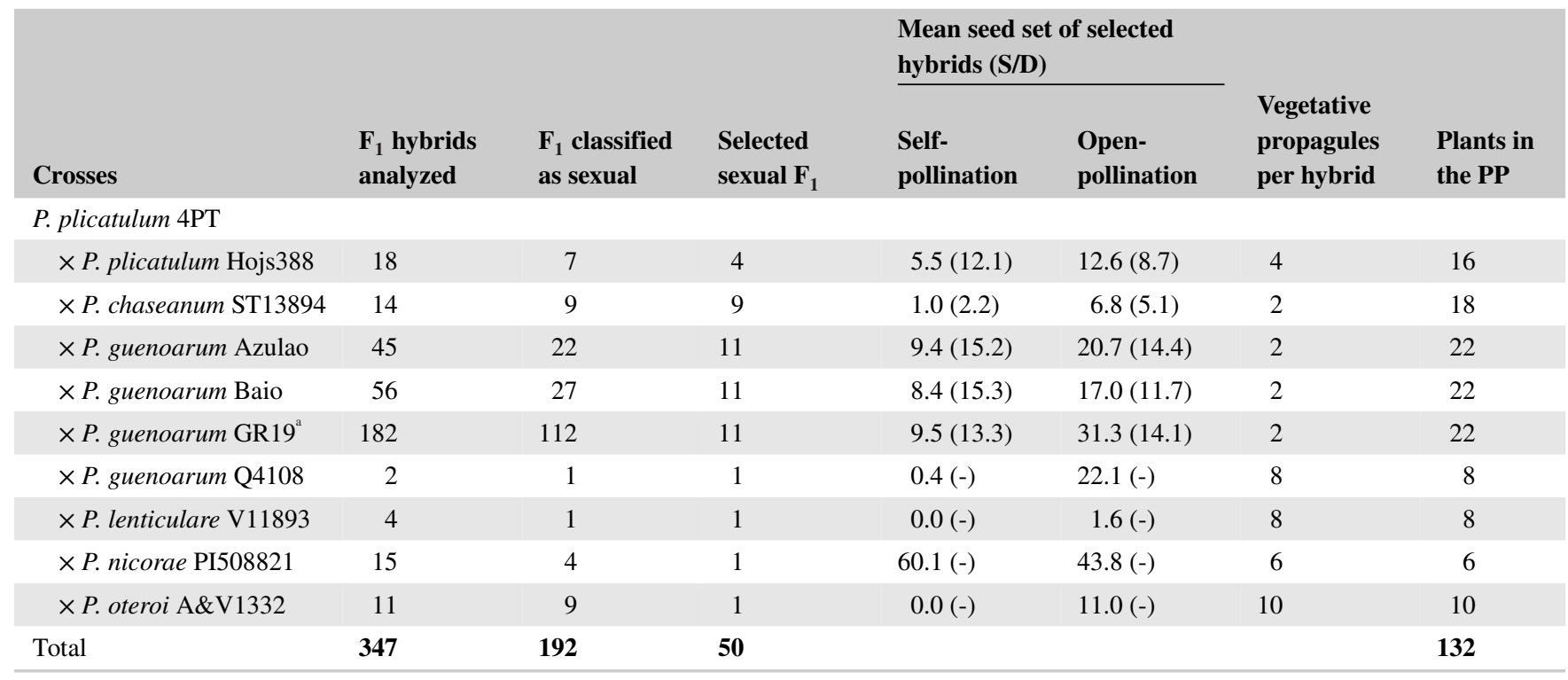

${ }^{\text {a} A g u i l e r a ~ e t ~ a l . ~} 2011$

2017), most of which (347) were classified for reproductive mode by flow cytometric seed analysis according the DNA content between embryo and endosperm in mature seeds (Aguilera et al., 2015; Novo et al., 2013; Novo et al., 2016, $2017,2019)$. Apomictic hybrids and a few extremely weak or dead hybrids were discarded, leaving 192 sexual hybrids from which the $F_{1}$ genotypes used in the PP were selected (Table 1). Selection was based mainly on plant vigor and health assessed visually. The total number of hybrids previously obtained in each sexual $\times$ apomictic cross was quite variable depending upon the number of pollinated spikelets and the crossability expressed in each cross combination (Novo et al., 2017). In addition, the proportion of vigorous plants in each progeny was also variable. Thus, very unequal numbers of vigorous sexual hybrids from each cross combination were available to form the PP. Hybrids were cloned by vegetative cuttings collected in the field and grown in pots containing $500 \mathrm{~cm}^{3}$ of sterilized soil. The number of propagules per hybrid was arbitrarily decided in order to build a PP in which every hybrid family and every one of the selected sexual hybrids would have similar chances to cross with each other (Table 1). Similarly, the potted plants were transplanted one meter apart in the field, distributed in a manner that clones of each hybrid family and clones of each particular hybrid were uniformly distributed over the PP. An approximately equal number of mature inflorescences from each individual plant were harvested, threshed, and the empty spikelets separated from those that set seed.

\section{4 | The sexual synthetic tetraploid population and phenotypic selection}

The total amount of seed obtained from PP was thoroughly mixed. A portion of this mixture was sown early the following spring, the seedlings transplanted to speedling planter flats, then transplanted to the field in mid-spring to establish a plantspaced SSTP. Three actions were conducted in the SSTP during a 1-year cycle.

Firstly, visual selection on plant vigor was performed near mid-summer. The most vigorous plants were marked in the field with iron sticks to facilitate their further agronomic evaluation during the same annual growing cycle.

Secondly, the performance of the selected individual plants was carried out considering four agronomic traits: seed set, seed health (i.e., free from ergot [Claviceps paspali]), regrowth after flowering, and cold tolerance. The seed set and seed health were determined in four mature inflorescences of each plant as described above. To evaluate the regrowth at the end of the flowering period, two categories were considered: good regrowth and absence or poor regrowth. The cold tolerance was visually estimated one month after the first frost and the coldest day of the winter season when temperature, somewhat below $0{ }^{\circ} \mathrm{C}$, lasted for about two hours in the early morning. No dead plants were observed and the frost damage was estimated in a scale of 1 to 5 for decreasing injury.

Finally, an additional selection round was done in late winter of the first-year cycle by surveying all the individuals of the 
SSTP, except the plants selected in previous steps. This additional selection was primarily based on vigorous and healthy general plant appearance observed at the end of the less favorable season of the 1-year cycle.

\section{5 | Genotypic selection}

Some of the selected plants of the SSTP were used as female parents in crosses with two apomictic tetraploid genotypes of Paspalum guenoarum as testers: 'Azulao' and 'U100', both characterized by their good adaptation to local conditions. Crosses and seed processing were performed as previously described. In July, the cariopses were placed in germinators prepared in plastic trays with sterile soil. After germination, the seedlings were transplanted into speedlings trays and finally transferred to the experimental field following a randomized complete block design, with three repetitions and with three plants per replication.

The test crosses were evaluated for seed fertility in openpollination, cold tolerance, and biomass yield accumulated during one growing season.

Seed fertility was determined as previously described in three mature inflorescences from each plant. Cold tolerance was visually estimated as described above. To estimate plant growth during the growing season the plants were cut at $10 \mathrm{~cm}$ above ground level, the fresh material weighted in the field, a subsample was dried in an oven at $65^{\circ} \mathrm{C}$ for $48 \mathrm{~h}$ to determine the proportion of dry matter and the totality of herbage mass harvested per individual plant. Apomictic-parent heterosis values were calculated using the Fisher's Least Significant Difference (LSD) test for comparing mean differences between the test cross, and apomictic parents. Unless otherwise stated in the text, all differences refer to significance at $\mathrm{p}<.05$. A selection index was also calculated based on heterosis values for biomass yield, seed fertility and cold tolerance using equal weights. The data for each trait was transformed using the Normal Score Transformation before the index was calculated to have the data for the three traits within an equal range.

\section{3 | RESULTS}

\subsection{The polycross population of sexually reproducing hybrids}

A total of 192 sexual hybrids were available, including 9 intraspecific and 183 interspecific hybrids. Fifty of these hybrids were selected to form the polycross population (PP). Selection was conducted within hybrid families based on plant vigor. Since the number of hybrids was variable among families, and the proportion of vigorous plants was also variable, very different numbers of hybrids per family were selected. Each selected hybrid was vegetatively propagated to constitute the PP. The number of propagules per hybrid differed, depending upon the number of hybrids selected per family and the possibility of each hybrid to be propagated. When a single hybrid was selected in a particular family, it was propagated as much as possible so as to be well represented in the PP. A population of 132 plants was established in the field, space-planted $1 \mathrm{~m}$ by $1 \mathrm{~m}$ apart, distributed in 11 rows of 12 plants per row (Table 1). The propagules were deliberately distributed in the planting such that each hybrid and each family had, as nearly as possible, the opportunity to intercross with all other hybrids and families.

With the exception of $4 \mathrm{PT} \times P$. nicorae, all other selected sexual hybrids showed much higher seed production with open- than with self-pollination, suggesting a clear tendency to allogamy (Table 1). Reciprocal crosses were made with a few of the 50 selected hybrids (Table 2). The results of this random sample of reciprocal crosses indicated that some genotypes showed self-incompatibility, but also differing cross-compatibility depending upon the pollen-parent genotype. For example, A37 and A41 are two sibling genotypes of the same hybrid family. The reciprocal crosses A37 $\times \mathrm{A} 41$ and A41 $\times$ A 37 produced very few caryopses $(0.9 \%$ and $0.2 \%$ of spikelets formed caryopsis, respectively), indicating a high degree of cross-incompatibility, but also of selfincompatibility since the pollinated inflorescences had not been emasculated. However, A41 was cross-compatible and produced seed $(20.5 \%)$ when pollinated with genotype N10. In the cross $\mathrm{O} 8 \times \mathrm{L} 1$ genotype $\mathrm{O} 8$ failed to produce seed due to self-incompatibility as well as cross-incompatibility with L1. However, $18 \%$ of its spikelets formed caryopsis in the cross $\mathrm{O} 8 \times \mathrm{N} 10$.

Therefore, it was expected that most seed produced by cross-pollination in the PP would be hybrid. Notwithstanding, the 6 clones of the unique 4PT $\times P$. nicorae hybrid included in the PP would likely be self-fertilized because this hybrid was highly self-fertile (Table 1 ). The 6 propagules were uniformly spaced within the PP planting in order to increase the chances of all hybrids to be pollinated with this hybrid. In this way, this $4 \mathrm{PT} \times P$. nicorae sexual hybrid might easily transfer genes from its apomict parent (natural apomictic $P$. nicorae) to the SSTP by self pollination or via meiotically reduced pollen.

The PP of 132 plants was maintained in strict isolation from any natural or cultivated species of the Plicatula group and from any other species of Paspalum that could contaminate the seed formation in the PP with extraneous pollen. Flowering was fairly uniform among the 132 plants of the PP, though approximately $10 \%$ initiated flowering a few days earlier. The rapid progressive flowering led the entire PP to a phase in which all plant had some inflorescences simultaneously in anthesis (Figure 1A). The first seed harvest was the earlier flowering plants; the general harvest was conducted 
TA B L E 2 Degree of cross compatibility between hybrids used to form the polycross population. Illustrative reciprocal crosses between randomly chosen pairs of $\mathrm{F}_{1} \mathrm{~s}$ that were members of the same or from different hybrid families. Seed set is the percentage of spikelets that formed grain

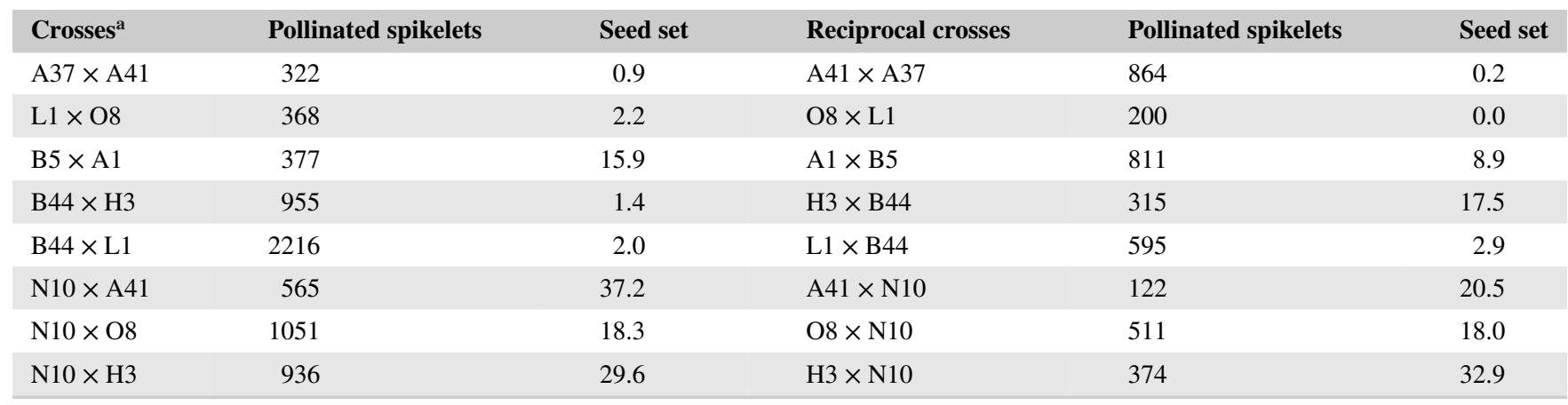

${ }^{a}$ Hybrids are identified by a capital letter followed by a number. The letter indicates the accession of the species used as male parent: the numbers indicate the specific hybrid of the corresponding family. A: Azulao (P. guenoarum); B: Baio (P. guenoarum); H: Hojs388 (P. plicatulum); L: V11893 (P. lenticulare); N: PI508821 (P. nicorae); O: A\&V1332 (P. oteroi).
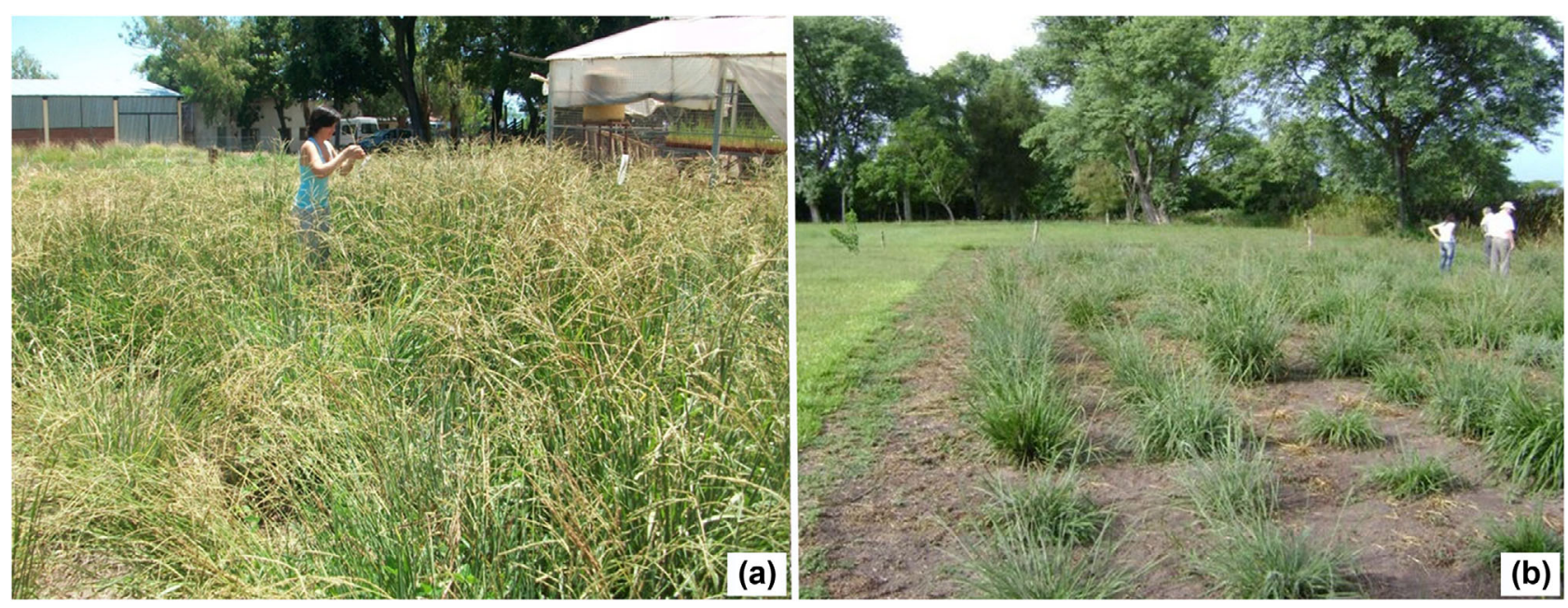

F I G U R E 1 Polycross population (PP) and sexual synthetic tetraploid population (SSTP). (a) The PP at full flowering stage. (b) Visual selection of the most vigorous and healthy plants in the highly variable SSTP

approximately 20 days after simultaneous blooming over the entire population was observed. Seeds from both harvests were mixed and stored under conditions of low temperature and humidity.

\section{2 | The sexual synthetic tetraploid population and phenotypic selection}

A random sample of 5 grams of the seed mixture harvested from the PP was germinated in sterilized soil. Seedlings at three-leaf stage were transplanted in speedling planter flats. Then, a total of 600 young plants were space-planted at $1 \mathrm{~m}$ by $1 \mathrm{~m}$ to the field in mid-spring (30 rows of 20 plants each). Large phenotypic variation was observed very soon; 60 plants died within fifteen days. The plants of the first three rows were transplanted to replace the dead plants. Thus, a uniform stand of 540 plants spaced $1 \mathrm{~m}$ by $1 \mathrm{~m}$ composed the final SSTP.
Aside from the seed used to generate the SSTP, remnant seed was saved in the gene bank.

The first selection was based on visually-assessed plant vigor (mainly plant size and health) at the initiation of flowering (Figure 1B). The 30 most vigorous plants, according the coincident judgments of at least three different researchers, were selected and marked with iron sticks. Then, the agronomic performance of these 30 plants was evaluated with respect to seed set (percentage of spikelets that formed grain); healthy seed set, i.e. the percentage of spikelets that set seed free of ergot, Claviceps paspali; plant regrowth after complete flowering at the beginning of the fall; and cold tolerance during winter. Six out of 30 primarily selected plants were discarded due to their very negative values mainly in seed set and cold tolerance. As expected since the SSTP originated mainly from interspecific crosses, wide variability was observed for all these agronomic traits. The wide range of variability is shown in Figure 2 for the 24 selected plants. Interestingly, 


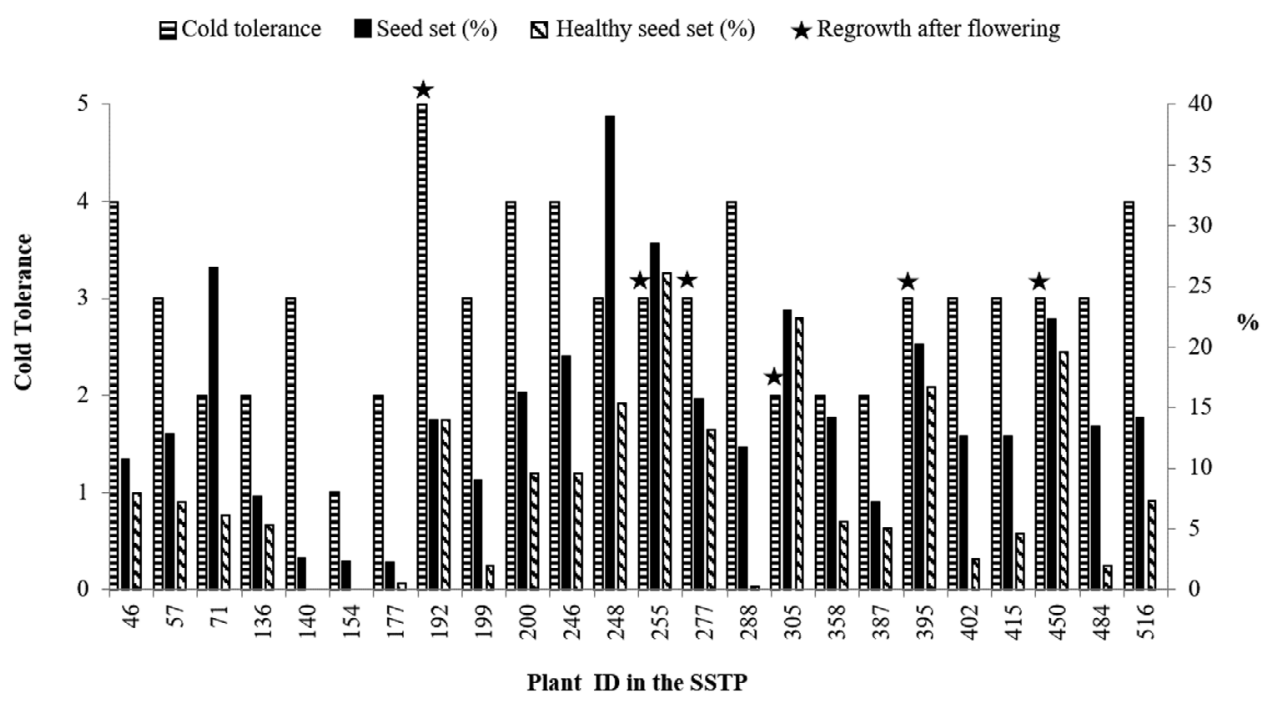

F I G U R E 2 Variability of agronomic performances of the best 24 plants of SSTP according the evaluation with respect to seed set (percentage of spikelets that formed grain); healthy seed set, i.e. the percentage of spikelets that set seed free of ergot, Claviceps paspali; plant regrowth after complete flowering at the beginning of fall, indicated by stars (Star: good regrowth; Lack of Star: absence or poor regrowth); and cold tolerance during winter

most of these plants showed seed set values over $10 \%$, an important rate considering their interspecific origin.

An additional selection was conducted near the end of the cold season and 7 plants were added to the selected group of 24 plants. The 7 plants were, at that time, similar in vigor to the first group of selected plants, and had showed superior regrowth during the fall and cold tolerance during the winter, or had some special phenotypic characteristic (for example the development of stolons) not seen in other plants. In consequence, a group of 31 sexual tetraploid plants from 540 of the SSTP were retained based on phenotype after the first year-cycle of selection.

\section{3 | Genotypic selection}

Of the 31 selected plants based on phenotype, twenty-five were used as female parents; nine plants (\#27, \#46, \#71, \#136, $\# 144, \# 200, \# 255$, \#358, \#415) were crossed by the two testers (P. guenoarum [Azulao and U100]), eight (\#177, \#183 \#199, \#222, \#237, \#305, \#395, \#402) crossed only by one tester Azulao, and the remaining eight plants (\#57, \#86, \#103, \#192, \#246, \#248, \#277, \#407) were crossed with U100. Six selected plants were not used as female parents in test crosses due to some practical difficulties that arose in crossing procedures, mainly due to asynchronous flowering with testers.

Difference among test crosses were observed for apomictic-parent heterosis for biomass yield, seed fertility and cold tolerance (Table 3). There was not a significant interaction between test cross and year for biomass yield or cold tolerance. Although positive heterosis values were observed for some test crosses across traits, most positive values were for cold tolerance (Table 3).

A selection index was calculated based on heterosis values for biomass yield, seed fertility and cold tolerance with equal weights (Figure 3). This index was used to identify the top 10 sexual genotypes from the SSTP (Figure 3).

\section{4 | DISCUSSION}

In breeding programs of apomictic tetraploid Paspalum species, it is possible to obtain sexual tetraploid plants by doubling the chromosome number of conspecific sexual diploid cytotypes or closely related, sexual diploid species. Induced sexual $4 \mathrm{x}$ plants constitute female parents for crosses with natural $4 \mathrm{x}$ apomicts. The proposed dominant monogenic control of the trait and the available tools to distinguish sexual from apomictic individuals are very feasible, reliable, and efficient, specially the flow-cytometric analysis to establish the embryo:endosperm DNA content ratio in mature seeds. All these possibilities recently facilitated the registration of 'Boyero UNNE' bahiagrass ( $P$. notatum Flüggé), the first apomictic tetraploid cultivar in the genus Paspalum to be obtained through artificial hybridization and selection (Urbani et al., 2017). Interestingly, the source of sexuality to develop this cultivar was the highly sexual Q3664 genotype (also named SWSB for sexual white stigma bahiagrass) derived through hybridization from the breeding project conducted by Glenn W. Burton at Tifton, GA, in the 1960s (Quarin et al., 2003). Despite additional sexual tetraploidized plants being obtained (Quarin, Espinoza, 
TA B L E 3 Apomictic-parent heterosis for biomass yield, seed fertility and cold tolerance in test crosses resulted from crossing genotypes from a sexual synthetic tetraploid population (SSTP) and two testers belonging to P. guenoarum (Azulao and U100). Heterosis was calculated as the mean difference between the test cross and the apomictic parent

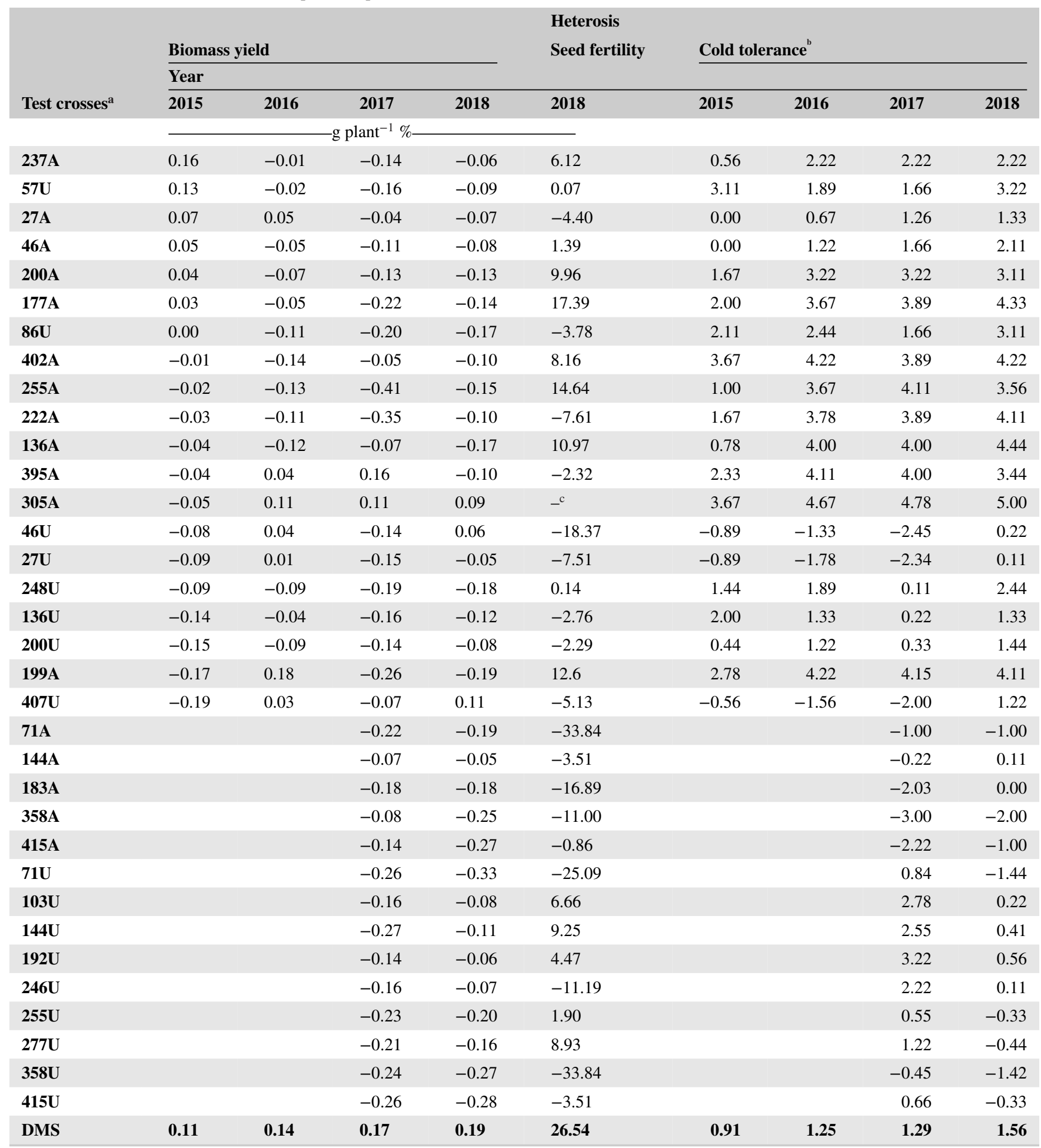

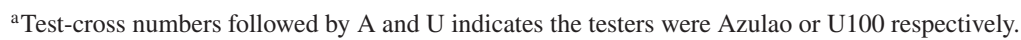

${ }^{b}$ Estimated using a visual scale varying from 1 to 5 , where 1 represented the lowest and 5 the highest.

${ }^{\mathrm{c}}$ This plant died in 2018 before flowering. 


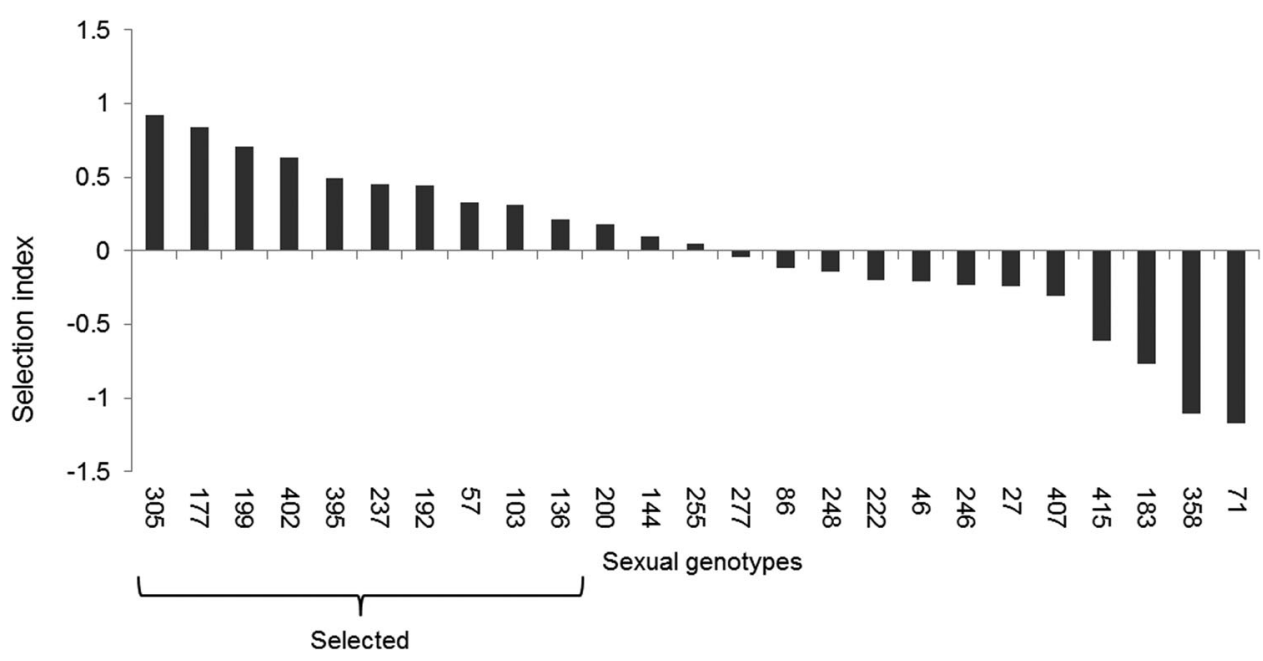

F I G U R E 3 Selection of a group of genotypes from a sexual synthetic tetraploid population of the Plicatula group of Paspalum based on combining ability. The selection index was calculated based on heterosis values for biomass yield, seed fertility and cold tolerance with equal weights

Martínez, Pessino, \& Bovo, 2001; Quesenberry et al., 2003), few sexual tetraploid bahiagrass genotypes were available for crosses. These genotypes were crossed with several naturally occurring apomictic tetraploid genotypes. All hybrid families were comprised of sexual and apomictic individuals. Intercrossing 29 sexual $F_{1}$ individuals from different hybrid families a SSTP was generated in order to widen the gene pool of the newly acquired sexual tetraploid bahiagrass plants (Zilli et al., 2018). The origin of the SSTP suggests that its individual constituents are carrying, as a whole, a wide genetic variation from different natural apomictic tetraploid accessions of bahiagrass from different geographic origins (Zilli et al., 2018). Since the individuals of SSTP are all sexual, they constitute a special gene pool enriched from different apomictic tetraploids of bahiagrass. In comparison with our results, this SSTP was established with sexual hybrids obtained with three experimental sexual tetraploid genotypes crossed with several natural apomictic tetraploids, all belonging to the same species. So, the hybrids of the SSTP were, as expected, quite fertile and the general plant vigor was far less variable than in our SSTP which was established from mostly interspecific hybrids. For this reason, we decided to conduct a rapid selection addressed to discard less vigorous plant and to retain the best seeders.

We developed a large SSTP by recombining sexual interand intraspecific hybrids obtained from crosses between a tetraploidized sexual genotype of P. plicatulum and 6 different apomictic tetraploid species of the Plicatula group, including one natural accession of $P$. plicatulum. The breeding procedures that generated the top 10 genotypes selected among the SSTP suggest that this elite group should carry a mixture of alleles from at least some of the 9 natural apomictic tetraploid accessions of 6 different species. This is expected because all hybrids, with the exception of $P$. plicatulum $4 \mathrm{PT} \times P$. nicorae
PI508821, produced seed preferentially by open pollination rather than by self pollination, a characteristic likely inherited from the induced mother plant. The high seed set in $P$. plicatulum 4PT $\times$ P. nicorae PI508821 hybrid, especially under self-pollination conditions, was previously attributed to its fairly regular meiotic chromosome behavior. Its female parent was an autotetraploidized plant, and the male parent species was suggested to be a natural autotetraploid or a segmental allotetraploid based on its cytogenetic characteristics (Burson $\&$ Bennett, 1970). The interspecific hybrid showed a high degree of bivalent pairing with quite few quadrivalents, and it was estimated that allosyndetic chromosome pairing was very low while autosyndesis was very important (Novo, Galdeano, Espinoza, \& Quarin, 2019). This meiotic behavior of the hybrid mimics the meiotic behavior of natural sexual allotetraploid species of Paspalum, as for example P. urvillei Steud., or yellow-anthered $P$. dilatatum Poir. (Caponio \& Quarin, 1990). Allopolyploid species of Paspalum are usually sexual, self-fertile, and good seeders. Six clones of the $P$. plicatulum 4PT $\times P$. nicorae PI508821 integrated the PP. The seed produced by this hybrid would transmit alleles from its parents either through self- or open-pollination and, in addition, alleles of its parents would be transmitted by its male gametes to some seeds formed by other hybrids of the PP. Only six clones of this hybrid were distributed in the PP intending to balance the incidence of $P$. nicorae's genes with genes of other apomictic parents in total seed production of the PP.

A large range of variability was observed for plant size, vigor, time of flowering, and seed yield in the SSTP population. In fact, $10 \%$ of 600 hybrids transplanted to the field died within a few days, and the remaining 540 plants showed a wide range of plant size. It was considered that good seed set and superior plant growth were the most important 
characteristics to form the selected group of future mother plants. The regrowth after flowering and cold tolerance also were considered because, in future breeding programs, it would be important to improve species of the Plicatula group to be cultivated in temperate regions, since they predominantly inhabit tropical or subtropical regions. A two-step procedure was used to select a group of elite genotypes from the SSTP. A group of 31 genotypes were selected based on their phenotype. Due to practical difficulties with hybridization procedures, only 25 of them were included in test crosses. Finally, 10 out of these 25 were selected based on their combining ability when crossed to one or two testers belonging to $P$. guenoarum. Variation among test crosses allowed selection of the best genotypes. The lack of test cross $\times$ year interaction for biomass yield and cold tolerance was a strong indication of the consistency of the data used for selection.

This elite group will be the basis for addressing several objectives in forage plant breeding. For instance, to initiate a program of recurrent selection based on combining ability these elite genotypes can be polycrossed to generate the first selection cycle. This new and improved population is expected to accumulate additive and non-additive genetic effects (Marcón et al., 2019a), so crosses with apomictic genotypes may result in improved sexual and apomictic hybrids. Also, this population can be improved using restricted recurrent phenotypic selection as was proposed for diploid bahiagrass (Burton, 1974), and successfully used for improving tetraploid bahiagrass (Marcón et al., 2019b). In addition, the elite group would constitute a special tetraploid germplasm to conserve genetic variability of the Plicatula group, and would be easy to use in breeding programs, since all natural tetraploid species of the group are apomictic. Mixed seed from a polycross among 50 mainly interspecific sexual $\mathrm{F}_{1}$ hybrids are conserved in a gene bank.

Despite the remarkable phenotypic variation observed in the elite group, an analysis of the genetic variability is still necessary in order to determine to what extent that variability has been transferred from a wide apomictic gene pool of several species of Plicatula group, to an experimental, sexual $4 \mathrm{x}$ genotype of $P$. plicatulum. Gene transfer is to be expected because previous works demonstrated that, once a sexual tetraploid was originated, interspecific hybridizations with different species of the Plicatula group was feasible, though the degree of crossability varied greatly depending on the species and the genotype used (Novo et al., 2017).

This elite group of sexual synthetic tetraploid plants opens a number of possibilities for plant breeding in the Plicatula, an informal infrageneric group of Paspalum which includes approximately 30 species of valuable forage grass constituents in native grasslands of the Americas. It makes possible genetic recombination in breeding programs from a gene pool heretofore captured in apomictic tetraploids.

\section{ACKNOWLEDGMENTS}

Patricia Novo received a fellowship from Consejo Nacional de Investigaciones Científicas y Técnicas (CONICET). Carlos Acuña, Florencia Galdeano, and Francisco Espinoza are members of CONICET. Patricia Novo, Carlos Acuña, Mario Urbani, Florencia Galdeano, Francisco Espinoza, and Camilo Quarin are members of the teaching or research staff of Facultad de Ciencias Agrarias, Universidad Nacional del Nordeste. Thanks are due to Dr. John Miles for reviewing the manuscript, including English grammatical issues, and to Dr. Elsa A. Brugnoli for her help and suggestions on statistics. Thanks are also due to Edmundo Barrios, Dante Galeano, and students of FCA-UNNE for their collaboration in field tasks. This study was supported by the FCA-PGG Wrightson Seeds agreement, Secretaría General de Ciencia y Técnica, UNNE and the Agencia Nacional de Promoción Científica y Tecnológica (ANPCyT), Argentina, PICT/2015 No. 0158.

\section{ORCID}

Carlos A. Acuña (D) https://orcid.org/0000-0002-8878-086X Francisco Espinoza (1D

https://orcid.org/0000-0001-7442-4920

\section{REFERENCES}

Acuña, C. A., Martínez, E. J., Zilli, A. L., Brugnoli, E. A., Espinoza, F., Marcón, F., ... Quarin, C. L. (2019). Reproductive systems in Paspalum: Relevance for germplasm collection and conservation, breeding techniques, and adoption of released cultivars. Frontiers in Plant Science, 10. https://doi.org/10.3389/fpls.2019.01377

Aguilera, P. M., Sartor, M. E., Galdeano, F., Espinoza, F., \& Quarin, C. L. (2011). Interspecific tetraploid hybrids between two forage grass species: Sexual Paspalum plicatulum and apomictic P. guenoarum. Crop Science, 51, 1544-1550. https://doi.org/10.2135/cropsci2010. 10.0610

Aguilera, P. M., Galdeano, F., Quarin, C. L., Ortiz, J. P. A., \& Espinoza, F. (2015). Inheritance of aposporous apomixis in interspecific hybrids derived from sexual Paspalum plicatulum and apomictic P. guenoarum. Crop Science, 55, 1947-1956. https://doi.org/10. 2135/cropsci2014.11.0770

Burson, B. L., \& Bennett, H. W. (1970). Cytology, method of reproduction, and fertility of Brunswickgrass, Paspalum nicorae Parodi. Crop Science, 10, 184-187.

Burton, G. W. (1974). Recurrent restricted phenotypic selection increases forage yields of Pensacola Bahiagrass. Crop Science, 14, 83-835. https://doi.org/10.2135/cropsci1974.0011183x0014000 $60016 \mathrm{x}$

Caponio, I., \& Quarin, C. L. (1990). Intra- and interspecific hybridization between Dallisgrass and Vaseygrass. Crop Science, 30, 362-364. https://doi.org/10.2135/cropsci1990.0011183x0030000 $20023 x$

Evers, G. W., \& Burson, B. L. (2004). Dallisgrass and other Paspalum species. In L. E. Moser, B. L. Burson, \& L. E. Sollenberger (Eds.), Warm-season (C4) grasses, Agronomy Monograph 45 ASA (pp. 681713). Madison, WI: CSSA, and SSSA.

Forbes, I., \& Burton, G. W. (1961). Cytology of diploids, natural and induced tetraploids, and intraspecific hybrids of bahiagrass, 
Paspalum notatum Flüggé. Crop Science, 1, 402-406. https://doi.org/ 10.2135/cropsci1961.0011183x000100060006x

Marcón, F., Martínez, E. J., Rodríguez, G. R., Zilli, A. L., Brugnoli, E. A., \& Acuña, C. A. (2019a). Genetic distance and the relationship with heterosis and reproductive behavior in tetraploid bahiagrass hybrids. Molecular Breeding, 39, 89. https://doi.org/10.1007/ s11032-019-0994-3

Marcón, F., Martínez, E. J., Zilli, A. L., Rodríguez, G. R., Brugnoli, E. A., \& Acuña, C. A. (2019b). Recurrent phenotypic selection and recurrent selection based on combining ability in tetraploid bahiagrass. Crop Science. https://doi.org/10.1002/csc2.20137

Matzk, F., Meister, A., \& Schubert, I. (2000). An efficient screen for reproductive pathways using mature seeds of monocots and dicots. Plant Journal, 21, 97-108. https://doi.org/10.1046/j.1365313x.2000.00647x

Miles, J. W. (2007). Apomixis for cultivar development in tropical forage grasses. Crop Science, 47, 238-249. https://doi.org/10.2135/ cropsci2007.04.0016IPBS

Novo, P. E., Espinoza, F., \& Quarin, C. L. (2013). An apomictic tetraploid Paspalum chaseanum cytotypes and its cytogenetic relationship with P. plicatulum (Poaceae): Taxonomic and genetic implications. Australian Journal of Botany, 61, 538-543. https://doi.org/ 10.1071/BT13194

Novo, P. E., Valls, J. F. M., Galdeano, F., Honfi, A. I., Espinoza, F., \& Quarin, C. L. (2016). Interspecific hybrids between Paspalum plicatulum and P. oteroi: A key tool for forage breeding. Scientia Agricola, 73, 356-361. https://doi.org/10.1590/0103-9016-2015-0218

Novo, P. E., Acuña, C. A., Quarin, C. L., Urbani, M. H., Marcón, F., \& Espinoza, F. (2017). Hybridization and heterosis in the Plicatula group of Paspalum. Euphytica, 213, 198. https://doi.org/10.1007/ s10681-017-1983-4

Novo, P. E., Galdeano, F., Espinoza, F., \& Quarin, C. L. (2019). Cytogenetic relationships, polyploid origin, and taxonomic issues in Paspalum species: Inter- and intraspecific hybrids between a sexual synthetic autotetraploid and five wild apomictic tetraploid species. Plant Biology, 21, 266-277. https://doi.org/10.1111/plb.12931

Oram, R. N. (1990). Register of Australian herbage plant cultivars( 3 ed.). CSIRO Australia, Melbourne: Parchment Press.

Ortiz, J. P. A., Quarin, C. L., Pessino, S. C., Acuña, C., Martínez, E. J., Espinoza, F., ... Pupilli, F. (2013). Harnessing apomictic reproduction in grasses: What we have learned from Paspalum. Annals of Botany, 112, 767-787. https://doi.org/10.1093/aob/mct152

Pupilli, F., Cáceres, M. E., Quarin, C. L., \& Arcioni, S. (1997). Segregation analysis of RFLP markers reveals a tetrasomic inheritance in apomictic Paspalum simplex. Genome, 40, 822-828. https://doi.org/ 10.1139/g97-806
Quarin, C. L. (1992). The nature of apomixis and its origin in Panicoid grasses. Apomixis Newsletter, 5, 8-15.

Quarin, C. L., Norrmann, G. A., \& Espinoza, F. (1998). Evidence for autoploidy in apomictic Paspalum rufum. Hereditas, 129, 119-124. https://doi.org/10.1111/j.1601-5223.1998.00119x

Quarin, C. L., Espinoza, F., Martínez, E. J., Pessino, S. C., \& Bovo, O. A. (2001). A rise of ploidy level induces the expression of apomixis in Paspalum notatum. Sexual Plant Reproduction, 13, 243-249. https: //doi.org/10.1007/s004970100070

Quarin, C. L., Urbani, M. H., Blount, A. R., Martínez, E. J., Hack, C. M., \& Burton, G. (2003). Registration of Q4188 and Q4205, sexual tetraploid germplasm lines of bahiagrass. Crop Science, 43, 745-746. https://doi.org/10.2135/cropsci2003.7450

Quesenberry, K. H., \& Smith, R. (2003). Production of sexual tetraploid bahiagrass using in vitro chromosome doubling agents. In A. Hopkins \& R. Burker (Eds.), Molecular breeding of forage and turf. Dallas, TX: Third International Symposium.

Sartor, M. E., Quarin, C. L., \& Espinoza, F. (2009). Mode of reproduction of colchicine-induced Paspalum plicatulum tetraploids. Crop Science, 49, 1270-1276. https://doi.org/10.2135/cropsci2008. 05.0270

Stein, J., Quarin, C. L., Martínez, E. J., Pessino, S. C., \& Ortiz, J. P. A. (2004). Tetraploid races of Paspalum notatum show polysomic inheritance and preferential chromosome pairing around the aposporycontrolling locus. Theoretical and Applied Genetics, 109, 186-191. https://doi.org/10.1007/s00122-004-1614z

Urbani, M. H., Acuña, C. A., Doval, D. W., Sartor, M. E., Galdeano, F., and Blount, A. R., ... Quarin, C. L. (2017). Registration of 'Boyero UNNE' bahiagrass. Journal of Plant Registrations, 11, 26-32. https: //doi.org/10.3198/jpr2016.04.0021crc

Zilli, A., Acuña, C. A., Schulz, R., Brugnoli, E., Guidalevich, V., Quarin, C. L., \& Martínez, E. J. (2018). Widening the gene pool of sexual tetraploid bahiagrass: Generation and reproductive characterization of a sexual synthetic tetraploid population. Crop Science, 58, 762772. https://doi.org/10.2135/cropsci2017.07.0457

How to cite this article: Novo PE, Acuña CA, Urbani MH, Galdeano F, Espinoza F, Quarin CL. Genetic transfer from several apomictic tetraploid Paspalum species to an elite group of sexual plants. Crop Science. 2020;1-11. https://doi.org/10.1002/csc2.20173 